\title{
Flow-Diversion Treatment of Unruptured Saccular Anterior Communicating Artery Aneurysms: A Systematic Review and Meta-Analysis
}

(D)F. Cagnazzo, (D) N. Limbucci, (D) S. Nappini, (D). Renieri, (D) A. Rosi, (D)A. Laiso, (DD. Tiziano di Carlo, DP. Perrini, and (D). Mangiafico

\begin{abstract}
BACKGROUND: Flow diversion for anterior communicating artery aneurysms required further investigation.

PURPOSE: Our aim was to analyze outcomes after treatment of anterior communicating artery aneurysms with flow-diverter stents.

DATA SOURCES: A systematic search of 3 data bases was performed for studies published from 2008 to 2018.

STUDY SELECTION: According to the Preferred Reporting Items for Systematic Reviews and Meta-Analyses guidelines, we included studies reporting anterior communicating artery aneurysms treated with flow diversion.

DATA ANALYSIS: Random-effects meta-analysis was used to pool the following: aneurysm occlusion rate, complications, and factors influencing the studied outcomes.

DATA SYNTHESIS: We included 14 studies and 148 unruptured saccular anterior communicating artery aneurysms treated with flow diversion. The long-term complete/near-complete (O'Kelly-Marotta C-D) occlusion rate was 87.4\% (91/105; 95\% Cl, 81.3\%-93.6\%; $I^{2}=0 \%$ ) (mean radiologic follow-up of 11 months). The treatment-related complication rate was $8.6 \%\left(14 / 126 ; 95 \% \mathrm{Cl}, 4 \%-13.1 \% ; I^{2}=0 \%\right)$, with morbidity and mortality rates of $3.5 \%\left(5 / 126 ; 95 \% \mathrm{Cl}, 2 \%-7 \% ; \mathrm{I}^{2}=0 \%\right)$ and $2.5 \%\left(2 / 148 ; 95 \% \mathrm{Cl}, 0.3 \%-5 \%\right.$; $\left.\mathrm{I}^{2}=0 \%\right)$, respectively. Most complications were periprocedural (12/126 =7\%; $\left.95 \% \mathrm{Cl}, 3 \%-11 \% ; I^{2}=0 \%\right)$. Thromboembolic events were slightly higher compared with hemorrhagic complications $\left(10 / 126=6 \% ; 95 \% \mathrm{Cl}, 2 \%-10 \% ; I^{2}=0 \%\right.$ and $\left.4 / 126=3 \% ; 95 \% \mathrm{Cl}, 1 \%-6 \% ; I^{2}=0 \%\right)$. Branching arteries (A2 or the recurrent artery of Heubner) covered by the stent were occluded in $16 \%\left(7 / 34 ; 95 \% \mathrm{Cl}, 3.5 \%-28 \% ; \mathrm{I}^{2}=25 \%\right)$ of cases. Pre- and posttreatment low-dose and high-dose of antiplatelet therapy was not associated with significantly different complication and occlusion rates.
\end{abstract}

LIMITATIONS: We reviewed small and retrospective series.

CONCLUSIONS: Flow diversion for unruptured saccular anterior communicating artery aneurysms appears to be an effective alternative treatment for lesions difficult to treat with coiling or microsurgical clipping. The treatment-related complication rate was relatively low. However, larger studies are needed to confirm these results.

ABBREVIATIONS: AcomA = anterior communicating artery; ASA = acetylsalicylic acid; AT = antiplatelet therapy; $\mathrm{CP}=$ clopidogrel; IQR $=$ interquartile range; OKM = O'Kelly-Marotta; PRISMA = Preferred Reporting Items for Systematic Reviews and Meta-Analyses

A nterior communicating artery (AcomA) aneurysms are among the most common intracranial aneurysms. Determining the best treatment strategy for such lesions is often diffi-

Received October 14, 2018; accepted after revision December 23.

From the Interventional Neuroradiology Unit (F.C., N.L., S.N., L.R., A.R., A.L., S.M.), Careggi University Hospital, Florence, Italy; and Department of Neurosurgery (D.T.d.C., P.P.), Cisanello Hospital, University of Pisa, Pisa, Italy.

Please address correspondence to Federico Cagnazzo, MD, Interventional Neuroradiology Unit, AOU Careggi, CTO, Largo P Palagi 1, Florence 50134, Italy; e-mail: f.cagnazzo86@gmail.com

三 Indicates article with supplemental on-line tables.

Indicates article with supplemental on-line photos.

http://dx.doi.org/10.3174/ajnr.A5967 cult because AcomA aneurysms may present a therapeutic challenge for both clipping (deep location, anatomic variability, perforator arteries) ${ }^{1}$ and endovascular treatment (wide-neck lesions incorporating branching vessels). ${ }^{2}$ In addition, AcomA aneurysms may have a risk of rupture higher than those in other locations. ${ }^{3}$ On the basis of their ability to reconstruct the parent artery, the off-label uses of flow-diverter stents are constantly extended, especially for aneurysms with unfavorable anatomy. ${ }^{2,4,5}$ Flow-diversion treatment of complex AcomA aneurysms has been recently reported as an alternative strategy when conventional coiling or stent-assisted coiling is not a feasible option. However, data describing treatment-related outcomes of flow diversion for lesions located at the AcomA region are scanty, and the 
efficacy and safety of this technique remain unclear. Our metaanalysis examined occlusion rates and procedure-related complications of saccular unruptured AcomA aneurysms treated with flow-diverter stents.

\section{MATERIALS AND METHODS Literature Search}

A comprehensive literature search of PubMed, Ovid MEDLINE, and Ovid EMBASE was conducted for studies published from January 2008 to September 2018. The Preferred Reporting Items for Systematic Reviews and Meta-Analyses (PRISMA) guidelines ${ }^{6}$ were followed. The key words and the detailed search strategy are reported in On-line Table 1, and the studies included in our review are reported in On-line Table 2. The inclusion criterion was the following: studies reporting series with patients with unruptured AcomA aneurysms treated with flow-diverter stents. Exclusion criteria were the following: 1) case reports, 2) review articles, 3) studies published in languages other than English, 4) in vitro/ animal studies, and 5) series reporting aneurysms located at the $\mathrm{A} 1$ or distal to the AcomA region (A2, A3). In cases of overlapping patient populations, only the series with the largest number of patients or most detailed data were included. Two independent readers screened articles in their entirety to determine eligibility for inclusion. A third author solved discrepancies.

\section{Data Collection}

We extracted the following information: 1) technical success rate, 2) occlusion rate, 3 ) treatment-related complications, and 4) clinical outcome. Occlusion and complication rates were analyzed on the basis of the influence of the following: 1) aneurysm size (saccular aneurysms, small- and medium-sized versus large-giant);2) patient age (younger versus older than 60 years; 3 ) type of flowdiverter stents; 4) first treatment versus retreatment; and 5) flow diverter alone versus flow diverter plus coiling.

Complete/near-complete aneurysm occlusion was defined on the basis of the following: O'Kelly-Marotta (OKM) grade ${ }^{7} \mathrm{C}-\mathrm{D}$, when digital subtraction angiography follow-up was available or when "complete occlusion" and "neck remnant" were used in the study. Treatment-related complications were divided into the following: 1) periprocedural/early events (within 30 days) and delayed events (after 30 days); 2) transient (asymptomatic events or complete neurologic recovery) and permanent complications (symptomatic events with permanent deficits); and 3) ischemic and hemorrhagic complications. The angiographic outcome of covered arteries (A2 or the recurrent artery of Heubner) was evaluated as the following: 1) arterial narrowing, or 2) arterial occlusion. Finally, good outcome was defined as a modified Rankin Scale score of $0-2$ or a Glasgow Outcome Score of 4-5, or it was assumed if the study used the terms "no morbidity," "good recovery," or "no symptoms."

\section{Outcomes}

The primary objectives of this study were to define the safety (treatment-related complications, mortality rate, and neurologic outcomes) and the efficacy (technical success rate, angiographic occlusion) of AcomA aneurysms treated with flow diversion. The secondary objectives were to define the influence of aneurysm, patient, and treatment characteristics on the analyzed outcomes.

\section{Quality Scoring}

The Newcastle-Ottawa Scale ${ }^{8}$ was used for the quality assessment of the included studies (details in On-line Tables 3 and 4). The quality assessment was performed by 2 authors independently, and a third author solved discrepancies.

\section{Statistical Analysis}

We estimated, from each cohort, the cumulative prevalence (percentage) and 95\% confidence interval for each outcome. Heterogeneity of the data was assessed by the Higgins index $\left(\mathrm{I}^{2}\right)$, and subsequently, the DerSimonian and Laird random-effects model was applied. The graphic representation was performed with a forest plot. The meta-regression and funnel plot followed by the Egger linear regression test were analyzed, respectively, to evaluate the heterogeneity and bias. To compare the percentages and to calculate the $P$ values, we used a $Z$-test for 2 proportions. Differences were considered significant at $P<.05$. Meta-analysis was performed with ProMeta-2 (Internovi, Cesena, Italy) and OpenMeta[Analyst] (http://www.cebm.brown.edu/openmeta/).

\section{RESULTS}

\section{Literature Review}

Studies included in our meta-analysis are summarized in On-line Table 2. The search flow diagram is shown in On-line Fig 1.

Fourteen studies and 148 AcomA aneurysms treated with flow-diverter stents were included in our review.

\section{Quality of Studies}

Studies included in our review were the following: Eleven studies were retrospective single-center series, whereas 3 studies were prospective multicentric series. The latter studies were rated as "high-quality" studies. Details of the rating of the included studies are reported in On-line Tables 3 and 4.

\section{Patient Population and Aneurysm Characteristics}

Overall, 148 patients with unruptured saccular AcomA aneurysms were treated with flow-diverter stents (On-line Table 5). The mean age of patients was 57 years (range, $24-80$ years), and the proportion of male patients was $46 \%$ (95\% CI, 34\%-58\%). Mean aneurysm size was $6.2 \mathrm{~mm}$ (median, $5.5 \mathrm{~mm}$; interquartile range [IQR], 5-7 mm; range, 3-18 $\mathrm{mm}$ ). The proportion of previously ruptured aneurysms treated with other techniques in the acute phase was $60.4 \%$ (55/91; 95\% CI, 50\%-70\%), and the proportion of aneurysms recanalized and retreated with flow-diverter stents was 50.4\% (54/107; 95\% CI, 41\%-59\%).

\section{Treatment Characteristics}

The most common stent used was the Pipeline Embolization Device (PED; Covidien, Irvine, California) (97/148 = 65.6\%; $95 \%$ CI, 57\%-72\%), followed by the Flow-Redirection Endoluminal Device (FRED; MicroVention, Tustin, California) $(21 / 148=$ 14.2\%; 95\% CI, 9\%-21\%), the Silk flow diverter (Balt Extrusion, Montmorency, France) $(18 / 148=12.1 \%$; 95\% CI, 7\%-18\%), and the Surpass stent (Stryker Neurovascular, Kalamazoo, Michigan) $(12 / 148=8.1 \%$; $95 \% \mathrm{CI}, 4.4 \%-13 \%)$. The proportion of 


\begin{tabular}{|c|c|c|c|}
\hline Variables & $\begin{array}{c}\text { Results of Systematic } \\
\text { Review and } \\
\text { Meta-Analysis }\end{array}$ & $\begin{array}{c}\text { No. of } \\
\text { Articles }\end{array}$ & $\begin{array}{c}\text { Statistic } \\
(95 \% \mathrm{CI})\left(\mathrm{I}^{2}\right)\end{array}$ \\
\hline \multicolumn{4}{|l|}{ Angiographic outcomes } \\
\hline Rate of successful stent deployment & $142 / 145=95.5 \%$ & 13 & $(92-98)\left(I^{2}=0 \%\right)$ \\
\hline Immediate aneurysm occlusion rate (OKM C-D) & $5 / 35=14 \%$ & 4 & $(4-23)\left(I^{2}=19 \%\right)$ \\
\hline Long-term complete/near-complete occlusion rate (OKM C-D) & $91 / 105=87.4 \%$ & 10 & $(81.3-93.6)\left(I^{2}=0 \%\right)$ \\
\hline Long-term complete occlusion rate (OKM D) & $66 / 80=84.9 \%$ & 8 & $(76.8-93)\left(1^{2}=12.5 \%\right)$ \\
\hline \multicolumn{4}{|l|}{ Treatment-related complications and clinical outcomes } \\
\hline Overall treatment-related complications & $14 / 126=8.6 \%$ & 11 & $(4-13.1)\left(1^{2}==0 \%\right)$ \\
\hline Periprocedural/early complications (within 30 days) & $12 / 126=7 \%$ & 11 & $(3-11)\left(1^{2}=0 \%\right)$ \\
\hline Delayed complications (after 30 days) & $2 / 126=1.8 \%$ & 11 & $(1-5)\left(1^{2}=0 \%\right)$ \\
\hline Transient complications & $9 / 126=6 \%$ & 11 & $(2.7-11)\left(1^{2}=0 \%\right)$ \\
\hline Permanent complications & $5 / 126=3.5 \%$ & 11 & $(2-7)\left(1^{2}=0 \%\right)$ \\
\hline Treatment-related mortality & $2 / 148=2.5 \%$ & 14 & $(0.3-5)\left(1^{2}=0 \%\right)$ \\
\hline Overall rate of good neurologic outcome & $108 / 114=95 \%$ & 10 & $(93-98)\left(1^{2}=0 \%\right)$ \\
\hline \multicolumn{4}{|l|}{ Type of complications } \\
\hline Thromboembolic complications & $10 / 126=6 \%$ & 11 & $(2-10)\left(1^{2}=0 \%\right)$ \\
\hline Hemorrhagic complications & $4 / 126=3 \%$ & 11 & $(1-6)\left(1^{2}=0 \%\right)$ \\
\hline Acute in-stent thrombosis & $5 / 126=4 \%$ & 11 & $(1.3-8)\left(1^{2}=0 \%\right)$ \\
\hline Aneurysm rupture after treatment & $0 / 138=0 \%$ & 13 & \\
\hline Chronic in-stent stenosis (>50\%) & $2 / 75=4.8 \%$ & 8 & $(2-9)\left(1^{2}=0 \%\right)$ \\
\hline Overall flow changes on covered vessels & $12 / 34=28 \%$ & 4 & $(1.5-5)\left(1^{2}=76 \%\right)$ \\
\hline Rate of narrowing of covered vessel ${ }^{a}$ & $5 / 34=11 \%$ & 4 & $(0.7-20)\left(1^{2}=8 \%\right)$ \\
\hline Rate of occlusion of covered vessels ${ }^{\mathrm{a}}$ & $7 / 34=16 \%$ & 4 & $(3.5-28)\left(1^{2}=22 \%\right)$ \\
\hline
\end{tabular}

a Symptoms related to flow changes on the covered vessels (A2 or the recurrent artery of Heubner) were reported in 3 cases:l case of transitory hemiparesis due slow flow on the covered A2; 1 case of transient facial palsy due to the coverage of the artery of Heubner; and 1 case of asymptomatic stroke in the territory of the artery of Heubner 4 months after treatment.

patients treated with flow diversion plus coiling was $10.2 \%(10 /$ 98; 95\% CI, 5.4\%-17\%), and the proportion of patients treated with multiple stents was $6.7 \%(10 / 148 ; 95 \% \mathrm{CI}, 3.5 \%-12 \%)$. The mean radiologic (DSA) follow-up was 11 months (range, 4-18 months; median, 12 months; IQR, 9.7-12 months), and the mean clinical follow-up was 11 months (range, 6-19 months; median, 12 months; IQR, 6-12 months).

\section{Angiographic Outcomes}

The technical success rate was 95.5\% (142/145; 95\% CI, 92\%$98 \% ; \mathrm{I}^{2}=0 \%$ ) (Table). Immediate angiographic occlusion (OKM C-D) after treatment was obtained in $14 \%$ (5/35; 95\% CI, 4\%$23 \% ; \mathrm{I}^{2}=19 \%$ ) of aneurysms. The rate of long-term complete/ near-complete occlusion (OKM C-D) was 87.4\% (91/105; 95\% CI, $81.3 \%-93.6 \%$; $\left.\mathrm{I}^{2}=0 \%\right)$. Meta-regression showed a nonsignificant variation of the effect size $(P=.278)$, and the funnel plot, followed by the Egger linear regression test, excludes publication bias ( $P=.056)$ (On-line Fig 2). The rate of long-term complete occlusion (OKM D) was $84.9 \%\left(66 / 80 ; 95 \%\right.$ CI, 76.8\%-93\%; $\mathrm{I}^{2}=$ $12.5 \%)$.

\section{Treatment-Related Complications}

The overall complication rate was $8.6 \%$ (14/126; 95\% CI, 4\%$13.1 \%$; $\mathrm{I}^{2}=0 \%$ ) (Table). Meta-regression showed a significant decrease in the effect size $(P=.443)$ during the analyzed periods $(P=.022)$, whereas the funnel plot, followed by the Egger linear regression test, excludes publication bias $(P=.407)$ (On-line Fig 3). Periprocedural/early complications were $7 \%$ (12/126; 95\% CI, $\left.3 \%-11 \% ; \mathrm{I}^{2}=0 \%\right)$. Delayed complications were $1.8 \%(2 / 126$; $95 \%$ CI, $1 \%-5 \%$; $\left.\mathrm{I}^{2}=0 \%\right)$. Transient and permanent complications were $6 \%\left(9 / 126 ; 95 \% \mathrm{CI}, 2.7 \%-11 \% ; \mathrm{I}^{2}=0 \%\right)$ and $3.5 \%$ (5/126; 95\% CI, 2\%-7\%; $\left.\mathrm{I}^{2}=0 \%\right)$, respectively.
Overall, ischemic/thromboembolic, and hemorrhagic events were $6 \%\left(10 / 126 ; 95 \% \mathrm{CI}, 2 \%-10 \%\right.$; $\left.\mathrm{I}^{2}=0 \%\right)$ and $3 \%(4 / 126$; $95 \%$ CI, $\left.1 \%-6 \% ; I^{2}=0 \%\right)$, respectively. Hemorrhagic complications were related to intracerebral hemorrhages during the periprocedural period. In only 1 case was the intraparenchymal hematoma associated with permanent sequalae. The rate of acute in-stent thrombosis was $4 \%\left(5 / 126 ; 95 \% \mathrm{CI}, 1.3 \%-8 \%\right.$; $\left.\mathrm{I}^{2}=0 \%\right)$, whereas chronic in-stent stenosis $(>50 \%)$ was $4.8 \%(2 / 75 ; 95 \%$ CI, $2 \%-9 \%$; $\left.\mathrm{I}^{2}=0 \%\right)$. There were no cases of aneurysm rupture after treatment during follow-up.

The overall rate of flow modifications of vessels covered by flow diverters (A2 or artery of Heubner) was 28\% (12/34; 95\% CI, $\left.1.5 \%-5 \% ; \mathrm{I}^{2}=76 \%\right)$. The rate of occlusion of covered arteries during follow-up was $16 \%\left(7 / 34 ; 95 \% \mathrm{CI}, 3.5 \%-28 \%\right.$; $\left.\mathrm{I}^{2}=22 \%\right)$, whereas the rate of arterial narrowing was $11 \%(5 / 34 ; 95 \% \mathrm{CI}$, $\left.0.7 \%-20 \% ; I^{2}=8 \%\right)$. Symptoms related to flow changes on the covered A2 or the recurrent artery of Heubner were reported in 3 cases: 1 case of transitory hemiparesis due to slow flow on the covered A2 immediately after stent deployment, 1 case of transient facial palsy due to the coverage of the artery of Heubner, and 1 case of an asymptomatic ischemic lesion on the territory of the artery of Heubner that was detected with the MR imaging 4 months after treatment.

Treatment-related mortality was 2.5\% (2/148; 95\% CI, 0.3\%$5 \% ; \mathrm{I}^{2}=0 \%$ ), and the rate of good neurologic outcome was $95 \%$ $\left(108 / 114 ; 95 \%\right.$ CI, 93\%-98\%; $\left.\mathrm{I}^{2}=0 \%\right)$.

\section{Factors Related to Aneurysm Occlusion}

Overall, the occlusion rate was comparable among patients younger-versus-older than 60 years $(P=.7)$, type of flow-diverter stent, flow diversion as a first treatment or retreatment of recana- 
lized aneurysms, and flow diverter alone versus flow diverter plus coiling. There was a trend toward higher occlusion rates for aneurysms of small and medium-sized versus large-giant $(32 / 35=$ 90\%; 95\% CI, 80\%-95\%; $\mathrm{I}^{2}=0 \%$ versus $11 / 14=70 \%$; $95 \% \mathrm{CI}$, $\left.50 \%-85 \% ; \mathrm{I}^{2}=42 \%\right)(P=.07)$.

\section{Factors Related to Complications after Treatment}

There was no statistically significant difference in complication rates in relation to patient age, first treatment versus retreatment, and flow diverter with-versus-without coiling. Although not statistically significant, complications were higher for large/giant aneurysms $\left(3 / 14=20 \%\right.$; 95\% CI, 5\%-30\%; $\left.\mathrm{I}^{2}=0 \%\right)$ compared to small/medium sized lesions $\left(2 / 35=7 \%\right.$; $95 \%$ CI, 2\%-16\%; $\mathrm{I}^{2}=$ $0 \%)$. The PED was associated with $12 \%$ complications $(9 / 75 ; 95 \%$ CI, 6\%-21\%); the FRED stent, with $14 \%$ (3/21; 95\% CI, 4\%$30 \%)$; and the Silk stent, with 6\% (1/17; 95\% CI, 2\%-25\%). Only 1 series described treatment-related complications after using the Surpass stent, reporting no adverse events (On-line Table 6).

\section{Relationship between Antiplatelet Therapy and Treatment-Related Outcomes}

Antiplatelet therapy (AT) before treatment was dichotomized into 2 groups: acetylsalicylic acid (ASA), $81-160 \mathrm{mg}$, + clopidogrel (CP), $75 \mathrm{mg}$, and ASA, 250-325 mg, + CP, $75 \mathrm{mg}$, 3-7 days before treatment. The rate of periprocedural complications was $5 \%\left(1 / 20 ; 95 \% \mathrm{CI}, 4 \%-15 \% ; \mathrm{I}^{2}=0 \%\right)$ and $6 \%(3 / 40 ; 95 \% \mathrm{CI}$, $\left.2 \%-14 \% ; I^{2}=0 \%\right)(P=.8)$, respectively (On-line Tables 7-9).

AT therapy after treatment was dichotomized into the following groups: ASA, 81-100 mg. + CP, 75 mg, and ASA, 160-300 $\mathrm{mg}$, $+\mathrm{CP}, 75 \mathrm{mg}$, for 3-6 months. The rates of delayed complications were $0 \%(0 / 23)$ and $3.5 \%\left(1 / 28 ; 95 \% \mathrm{CI}, 3 \%-11 \%\right.$; $\mathrm{I}^{2}=$ $0 \%)(P=.36)$, respectively. Long-term occlusion rates (OKM grades C-D) were 94.5\% (28/29; 95\% CI, 86\%-98\%; $\left.\mathrm{I}^{2}=0 \%\right)$ and $88 \%\left(17 / 19 ; 95 \% \mathrm{CI}, 76 \%-94 \% ; \mathrm{I}^{2}=0 \%\right)(P=.41)$, respectively.

In addition, treatment-related outcomes were evaluated on the basis of the duration of the dual AT: "short" duration of the dual AT (ASA + CP until 3 months) versus "long" duration of the dual AT (at least until 6 months). In both groups, ASA was continued for about 1 year or for life. Overall, treatment-related complications were $5 \%\left(2 / 30 ; 95 \% \mathrm{CI}, 3 \%-12 \% ; \mathrm{I}^{2}=0 \%\right)$ and $6.5 \%$ (5/54; 95\% CI, 4\%-13\%; $\left.\mathrm{I}^{2}=0 \%\right)$ among the groups with short and long duration of the dual AT, respectively $(P=.77)$. Complete/near-complete occlusion rates were 93\% (25/27; 95\% CI, $\left.83 \%-98 \% ; \mathrm{I}^{2}=0 \%\right)$ and $91 \%\left(20 / 22 ; 95 \%\right.$ CI, 82\%-98\%; $\mathrm{I}^{2}=$ $0 \%$ ), among the groups with short and long duration of the dual AT, respectively $(P=.8)$.

\section{Study Heterogeneity}

Heterogeneity was low for all except 1 of the analyzed outcomes (the overall rate of flow changes among covered vessels).

\section{DISCUSSION}

When we combined data from 14 studies, our meta-analysis underlined several important findings related to the flow-diversion treatment of aneurysms originating from the AcomA region. In general, our results demonstrated that complex unruptured
AcomA aneurysms can be successfully treated with flow-diverter stents with a high rate of long-term angiographic occlusion and an acceptable rate of treatment-related complications.

\section{Angiographic Outcomes}

Successful stent deployment was achieved in $95.5 \%$ of cases, demonstrating that flow diversion is a straightforward technique even in complex anatomic situations such as the AcomA region. Given that aneurysm occlusion with flow-diverter stents is a progressive process, only $14 \%$ of aneurysms were occluded immediately after treatment, whereas $87 \%$ and $85 \%$ of the lesions presented with adequate (OKM C-D) and complete (OKM D) occlusion during 1 year of follow-up, respectively. In a large meta-analysis of nearly 1500 AcomA aneurysms treated endovascularly (excluding flowdiverter stents), Fang et $\mathrm{al}^{9}$ reported a quite high rate of immediate occlusion (88\%). However, although their immediate occlusion rate was higher compared with our results, complete/ near-complete occlusion during 6 months of follow-up was $85 \%$, underlining that long-term angiographic outcomes after flow diversion for AcomA aneurysms are comparable with other endovascular techniques.

Recently, intrasaccular flow disruption with the Woven EndoBridge device (WEB; Sequent Medical, Aliso Viejo, California) is increasingly used with promising results. However, series focusing on AcomA aneurysms showed approximately a 60\% longterm adequate occlusion after treatment with the WEB. ${ }^{10}$ In addition, emerging devices for neck protection, such as pCONus (phenox, Bochum, Germany) stents, have been developed to treat wide-neck bifurcation aneurysms. A recent series of 36 AcomA aneurysms treated with the pCONus showed an $80 \%$ complete/ near-complete occlusion rate. ${ }^{11}$ Finally, Y-stent-assisted coiling of AcomA aneurysms appears to be associated with $85 \%-$ $88 \%{ }^{12,13}$ complete/near-complete occlusion, though this technique is, in general, technically more complex. Accordingly, Ko et $\mathrm{al}^{12}$ reported 9 AcomA aneurysms treated with Y-stent placement. All of them were occluded during follow-up, but 2 patients experienced acute in-stent thrombosis and 1 patient had iatrogenic subarachnoid hemorrhage related to aneurysm perforation.

In our study, flow diversion was also effective for the treatment of recanalized AcomA aneurysms (On-line Table 6). Lin et $\mathrm{al}^{14}$ reported a small series of 6 AcomA aneurysms with recurrences after clipping; occlusion was achieved in 5 of them without treatment-related complications. This outcome is in accordance with those in larger series analyzing treatment-related outcomes of flow diversion used as a retreatment strategy. ${ }^{15}$ In addition, we found comparable angiographic results among AcomA aneurysms treated with flow diverters alone or in conjunction with coiling. When we investigated the literature, this result appears contradictory: Szikora et al, ${ }^{16}$ in a series of 19 wide-neck aneurysms, reported no differences in occlusion rates among lesions treated with or without coil packing, whereas Lin et $\mathrm{al}^{17}$ showed higher rates of complete occlusion in the group of aneurysms treated with the PED + coils. However, most aneurysms included in our review were unruptured, small lesions (mean size, $6 \mathrm{~mm}$ ), and additional coiling was not mandatory in most cases.

The device configuration was rarely reported in the included series, and outcome comparison between ipsilateral A1-A2 and 
ipsilateral A1 to contralateral A2 stent configuration was not possible. In the largest available series of AcomA aneurysms treated with flowdiverter stents, Colby et $\mathrm{al}^{2}$ described 41 patients treated with PEDs deployed from the ipsilateral A1 to the ipsilateral A2 in 94\% of patients and from the $\mathrm{A} 1$ to the contralateral $\mathrm{A} 2$ in the remaining $6 \%$ of patients. The authors reported $85 \%$ complete/near-complete occlusion and a $9 \%$ complication rate.

\section{Treatment-Related Complications}

Treatment-related morbidity after flow diversion in small or distal vessels is reported to be close to $10 \% .^{4,5,18}$ However, flow diversion for aneurysms arising from the AcomA complex should be considered separately due to the angioarchitecture and flow dynamics of this region that present the following: 1) frequent anatomic variations (such as the asymmetry of the A1 segments); 2) several perforating arteries supplying important structures such as the optic chiasm, the anterior hypothalamus, and the anterior perforated substance; and 3) the recurrent artery of Heubner (in general originating from the A1-A2 junction), which perfuses the striatum and the anterior limb of the internal capsule. ${ }^{1}$ Accordingly, injury to these arteries may result in a wide range of serious neurologic sequelae, including memory disorders, changes of personality, electrolyte imbalance, and motor deficits. ${ }^{1}$ When we investigated the literature, our meta-analysis found $8.6 \%$ of complications related to flow-diversion treatment of AcomA aneurysms. Most of them occurred in the periprocedural period after treatment (7\%). Permanent deficits and mortality related to the treatment were $3.5 \%$ and $2.5 \%$, respectively. Not surprising, ischemic events were the most common complications (6\%), together with acute in-stent thrombosis (4\%). Gawlitza et $\mathrm{al}^{19}$ reported 2 cases of transient ischemic complications ( 1 case of facial palsy and 1 case of lacunar infarct detected at MR imaging) related to the covered artery of Heubner. In a series of 9 AcomA aneurysms, Pierot et $\mathrm{al}^{20}$ reported 1 case of thromboembolism and 1 case of flow-diverter occlusion 4 days after treatment without permanent neurologic deficits.

Another important concern is the patency of the arteries covered with flow diverters. ${ }^{21}$ Despite very few studies focused on the angiographic outcome of the covered A2 segment (or main branching vessels such as the artery of Heubner), we found a $16 \%$ occlusion rate of jailed arteries during follow-up. Pistocchi et $\mathrm{al}^{22}$ reported 5 cases of occlusion and 4 cases of slow flow of the covered A2 segment among 14 patients with AcomA aneurysms treated with the Silk stent. In this series, only 1 patient experienced a transitory hemiparesis due to the sluggish flow on the covered A2, which regressed after blood pressure augmentation. Saleme et $\mathrm{al}^{23}{ }^{23}$ in a series of 9 AcomA aneurysms treated with the PED, described 2 cases of asymptomatic A2 occlusion during follow-up. In a recent meta-analysis of nearly 1200 supraclinoid internal carotid artery vessels covered with flow-diverter stents, the overall rate of occlusion was $7 \%$, with important differences among the ophthalmic artery (6\%), anterior choroidal artery $(1 \%)$, and posterior communicating artery $(20 \%),{ }^{21}$ with approximately $1 \%$ symptomatic occlusions. One of the most important mechanisms related to branch preservation is the pressure gradient between the artery and its covered branches. In general, when the occlusion progresses slowly, the collateral circulation can ef- ficiently supply the territory of the jailed artery and the occlusion can be tolerated in most cases.

Finally, meta-regression showed a significant $(P=.022)$ decrease of the complication rate during 7 years (from 2011 to 2018), probably due to improvement of the operator experience, 3D angiographic images, and better case selection and posttreatment patient management.

\section{Treatment-Related Outcomes Based on the AT}

We assessed pre- and posttreatment antiplatelet regimens dichotomizing the AT into 2 groups: pretreatment (3-7 days) low dose (ASA, 81-160 mg, + CP, $75 \mathrm{mg}$ ) and high dose (ASA, 250-325 $\mathrm{mg},+\mathrm{CP}, 75 \mathrm{mg}$ ) AT. Accordingly, we investigated the rate of intraprocedural/periprocedural complications showing $5 \%$ and $6 \%$ of treatment-related complications for low-dose and highdose AT, respectively $(P=.8)$.

Similarly, there were not statistically significant differences in complication and occlusion rates among groups with low-dose (ASA, 81-100 mg, + CP, $75 \mathrm{mg}$ ) and high-dose (ASA, 160-300 $\mathrm{mg},+\mathrm{CP}, 75 \mathrm{mg}$ ) AT regimens administrated during follow-up.

Our results are in accordance with a recent meta-analysis discussing the AT regimen used before and after using the PED. In this study, there was a lack of relationship between patients who received low- versus high-dose pre-PED ASA in terms of thromboembolic and hemorrhagic complications. ${ }^{24}$

\section{Strengths and Limitations}

Our study has several limitations. Series were often retrospective studies and small single-institution experiences. Because of the small number of cases, the comparison among subgroups may not provide power to show a statistically significant difference among the studied outcomes. Outcome comparison between ipsilateral A1-A2 and transcommunicating (from the A1 to the contralateral A2) stent configurations was not possible because of the scanty data. For the same reason, the asymmetry of the A1 segment was not evaluated. However, publication bias was reasonably excluded, and our review is the first and the largest study focusing on the flow-diversion treatment of AcomA aneurysms.

\section{CONCLUSIONS}

On the basis of our meta-analysis, flow diversion for unruptured saccular AcomA aneurysms appears to be an effective alternative treatment for lesions difficult to treat with coiling or microsurgical clipping. The treatment-related complication rate was relatively low, considering that flow-diverter stents are, in general, used for complex aneurysms of the AcomA region. However, larger studies are needed to confirm the safety and efficacy of this procedure.

Disclosures: Federico Cagnazzo-UNRELATED: Employment: University of Florence. Paolo Perrini-UNRELATED: Employment: University of Pisa.

\section{REFERENCES}

1. Hernesniemi J, Dashti R, Lehecka M, et al. Microneurosurgical management of anterior communicating artery aneurysms. Surg Neurol 2008;70:8-28; discussion 29 CrossRef Medline

2. Colby GP, Bender MT, Lin LM, et al. Endovascular flow diversion for treatment of anterior communicating artery region cerebral 
aneurysms: a single-center cohort of 50 cases. J Neurointerv Surg 2017;9:679-85 CrossRef Medline

3. Bijlenga P, Ebeling C, Jaegersberg M, et al; @neurIST Investigators. Risk of rupture of small anterior communicating artery aneurysms is similar to posterior circulation aneurysms. Stroke 2013;44: 3018-26 CrossRef Medline

4. Cagnazzo F, Mantilla D, Lefevre PH, et al. Treatment of middle cerebral artery aneurysms with flow-diverter stents: a systematic review and meta-analysis. AJNR Am J Neuroradiol 2017;38:2289-94 CrossRef Medline

5. Cagnazzo F, Cappucci M, Dargazanli C, et al. Treatment of distal anterior cerebral artery aneurysms with flow-diverter stents: a single-center experience. AJNR Am J Neuroradiol 2018;39:1100-06 CrossRef Medline

6. Moher D, Liberati A, Tetzlaff J, et al. Preferred reporting items for systematic reviews and meta-analyses: the PRISMA statement. Int J Surg 2010;8:336-41 CrossRef Medline

7. O'Kelly CJ, Krings T, Fiorella D, et al. A novel grading scale for the angiographic assessment of intracranial aneurysms treated using flow diverting stents. Interv Neuroradiol 2010;16:133-37 CrossRef Medline

8. Wells GA, Shea B, O'Connell D, et al. The Newcastle-Ottawa Scale (NOS) for assessing the quality of nonradomized studies in metaanalyses. Ottawa: Ottawa Hospital Research Institute; 2011. http://www. evidencebasedpublichealth.de/download/Newcastle_Ottowa_Scale_ Pope_Bruce.pdf. Accessed September 5, 2018

9. Fang S, Brinjikji W, Murad MH, et al. Endovascular treatment of anterior communicating artery aneurysms: a systematic review and meta-analysis. AJNR Am J Neuroradiol 2014;35:943-47 CrossRef Medline

10. Gherasim DN, Gory B, Sivan-Hoffmann R, et al. Endovascular treatment of wide-neck anterior communicating artery aneurysms using WEB-DL and WEB-SL: short-term results in a multicenter study. AJNR Am J Neuroradiol 2015;36:1150-54 CrossRef Medline

11. Labeyrie PE, Gory B, Aguilar-Perez M, et al. The pCONus device for treatment of complex wide-neck anterior communicating artery aneurysms. World Neurosurg 2017;101:498-505 CrossRef Medline

12. Ko JK, Han IH, Cho WH, et al. Crossing Y-stent technique with dual open-cell stents for coiling of wide-necked bifurcation aneurysms. Clin Neurol Neurosurg 2015;132:54-60 CrossRef Medline

13. Limbucci N, Renieri L, Nappini S, et al. Y-stent assisted coiling of bifurcation aneurysms with Enterprise stent: long-term follow-up. J Neurointerv Surg 2016;8:158-62 CrossRef Medline

14. Lin LM, Iyer RR, Bender MT, et al. Rescue treatment with Pipeline embolization for postsurgical clipping recurrences of anterior communicating artery region aneurysms. Interv Neurol 2017;6: 135-46 CrossRef Medline

15. Daou B, Starke RM, Chalouhi N, et al. The use of the Pipeline Embolization Device in the management of recurrent previously coiled cerebral aneurysms. Neurosurgery 2015;77:692-97; discussion 697 CrossRef Medline

16. Szikora I, Berentei Z, Kulcsar Z, et al. Treatment of intracranial aneurysms by functional reconstruction of the parent artery: the Budapest experience with the Pipeline Embolization Device. AJNR Am J Neuroradiol 2010;31:1139-47 CrossRef Medline

17. Lin N, Brouillard AM, Krishna C, et al. Use of coils in conjunction with the Pipeline embolization device for treatment of intracranial aneurysms. Neurosurgery 2015;76:142-49 CrossRef Medline
18. Yan Y, Zhu D, Tang H, et al. Safety and efficacy of flow diverter treatment for aneurysm in small cerebral vessels: a systematic review and meta-analysis. World Neurosurg 2018;115:54-64 CrossRef Medline

19. Gawlitza M, Januel AC, Tall P, et al. Flow diversion treatment of complex bifurcation aneurysms beyond the circle of Willis: a single-center series with special emphasis on covered cortical branches and perforating arteries. J Neurointerv Surg 2016;8: 481-87 CrossRef Medline

20. Pierot L, Spelle L, Berge J, et al. Feasibility, complications, morbidity, and mortality results at 6 months for aneurysm treatment with the Flow Re-Direction Endoluminal Device: report of SAFE study. J Neurointerv Surg 2018;10:765-70 CrossRef Medline

21. Cagnazzo F, Lefevre PH, Mantilla D, et al. Patency of the supraclinoid internal carotid artery branches after flow-diversion treatment: a meta-analysis. J Neuroradiol 2018 Aug 9. [Epub ahead of print] CrossRef Medline

22. Pistocchi S, Blanc R, Bartolini B, et al. Flow diverters at and beyond the level of the circle of Willis for the treatment of intracranial aneurysms. Stroke 2012;43:1032-38 CrossRef Medline

23. Saleme S, Iosif C, Ponomarjova S, et al. Flow-diverting stents for intracranial bifurcation aneurysm treatment. Neurosurgery 2014; 75:623-31; quiz 631 CrossRef Medline

24. Texakalidis P, Bekelis K, Atallah E, et al. Flow diversion with the Pipeline Embolization Device for patients with intracranial aneurysms and antiplatelet therapy: a systematic literature review. Clin Neurol Neurosurg 2017;161:78-87 CrossRef Medline

25. Toma AK, Robertson F, Wong K, et al. Early single centre experience of flow diverting stents for the treatment of cerebral aneurysms. $\mathrm{BrJ}$ Neurosurg 2013;27:622-28 CrossRef Medline

26. Clarencon F, Di Maria F, Gabrieli J, et al. Flow diverter stents for the treatment of anterior cerebral artery aneurysms: safety and effectiveness. Clin Neuroradiol 2017;27:51-56 CrossRef Medline

27. Dabus G, Grossberg JA, Cawley CM, et al. Treatment of complex anterior cerebral artery aneurysms with Pipeline flow diversion: mid-term results. J Neurointerv Surg 2017;9:147-51 CrossRef Medline

28. Möhlenbruch MA, Kizilkilic O, Killer-Oberpfalzer M, et al. Multicenter experience with FRED Jr flow re-direction endoluminal device for intracranial aneurysms in small arteries. AJNR Am J Neuroradiol 2017;38:1959-65 CrossRef Medline

29. Wakhloo AK, Lylyk P, de Vries J, et al; Surpass Study Group. Surpass flow diverter in the treatment of intracranial aneurysms: a prospective multicenter study. AJNR Am J Neuroradiol 2015;36:98-107 CrossRef Medline

30. Lin LM, Bender MT, Colby GP, et al. Use of a next-generation multidurometer long guide sheath for triaxial access in flow diversion: experience in 95 consecutive cases. J Neurointerv Surg 2018;10: 137-42 CrossRef Medline

31. Sultan-Qurraie A, Sattar A, Wazni W, et al. Anterior communicating artery aneurysm treatment with the Pipeline Embolization Device: a single-center experience with long-term follow-up. Interv Neurol 2017;6:126-34 CrossRef Medline

32. Lin LM, Jiang B, Bender MT, et al. 47 consecutive cases of Pipeline Flex flow diversion utilizing a novel large-bore intracranial intermediate catheter: nuances and institutional experience with the Syphontrak. Interv Neurol 2018;7:153-63 CrossRef Medline 